\title{
The improvement of SOC sequestration mediated by soil structure in the greenhouse vegetable soil converted from paddy field
}

\author{
Yijie Shi ${ }^{1}$, Meiyan Wang ${ }^{1}$, Tongyan $\mathrm{Yao}^{1}$, Lingying $\mathrm{Xu}^{1}$, and Xuezheng $\mathrm{Shi}^{1}$ \\ ${ }^{1}$ Institute of Soil Science Chinese Academy of Sciences
}

December 31, 2021

\begin{abstract}
Objective of investigation: Land use conversion strongly alters soil structure and substantially affects soil organic carbon (SOC) sequestration. Changing from an anaerobic paddy field $(\mathrm{PF})$ to a dry land easily causes SOC loss due to stimulation of $\mathrm{C}$ decomposition. However, no evidence of SOC loss from PF to intensive vegetable cultivation has been certainly presented. Experimental material: This study was conducted on the long-term cultivated open-field vegetable (OFV) and greenhouse vegetable (GHV) planting area converted from old PF in China. Undisturbed soil cores, natural structured soil, and disturbed soil from top soil layers were using for further analyses. Methods of investigation: To comprehensively investigate SOC and soil structure change in the land use conversion of PF to OFV and PF to GHV, we used 13C-CPMAS NMR spectroscopy to classify the SOC fractions. The soil macropores $(>50 \mu \mathrm{m})$ was valued by X-ray computed tomography, and soil aggregates distribution was determined by wet sieving method. Data collection: Data were obtained from the above-mentioned measurements and statistically analyzed in R. Results: The result showed that the SOC stock increased 1-fold from PF to GHV. SOC stability increased with recalcitrant $\mathrm{C}$ (aromatic-C and carbonyl-C) raised by $21 \%-27 \%$ in GHV bulk soil. Both macropores and macroaggregates $(>250 \mu \mathrm{m})$ increased in GHV, accompanied by an accumulation of recalcitrant $\mathrm{C}$ in large macroaggregates. Conclusions: we confirmed the expanded GHV cultivation sequestered more belowground SOC than PF, associated with the amplified physical protection by enhancing soil aggregation and by redistributing of soil macropores.
\end{abstract}

\section{Hosted file}

Manuscript_LDD_2.docx available at https://authorea.com/users/453361/articles/551209-theimprovement-of-soc-sequestration-mediated-by-soil-structure-in-the-greenhouse-vegetablesoil-converted-from-paddy-field

\section{Hosted file}

Table.docx available at https://authorea.com/users/453361/articles/551209-the-improvementof-soc-sequestration-mediated-by-soil-structure-in-the-greenhouse-vegetable-soilconverted-from-paddy-field 

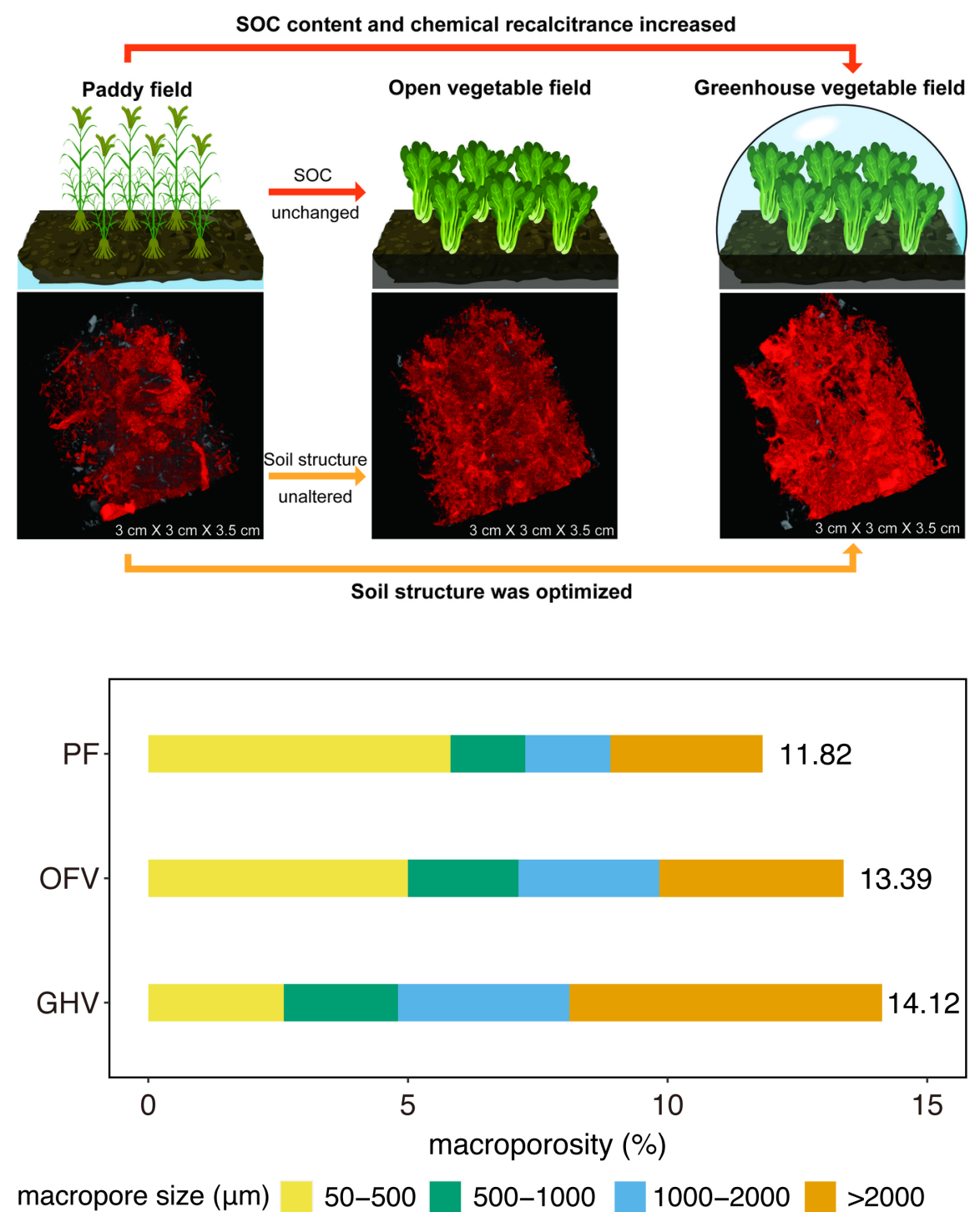

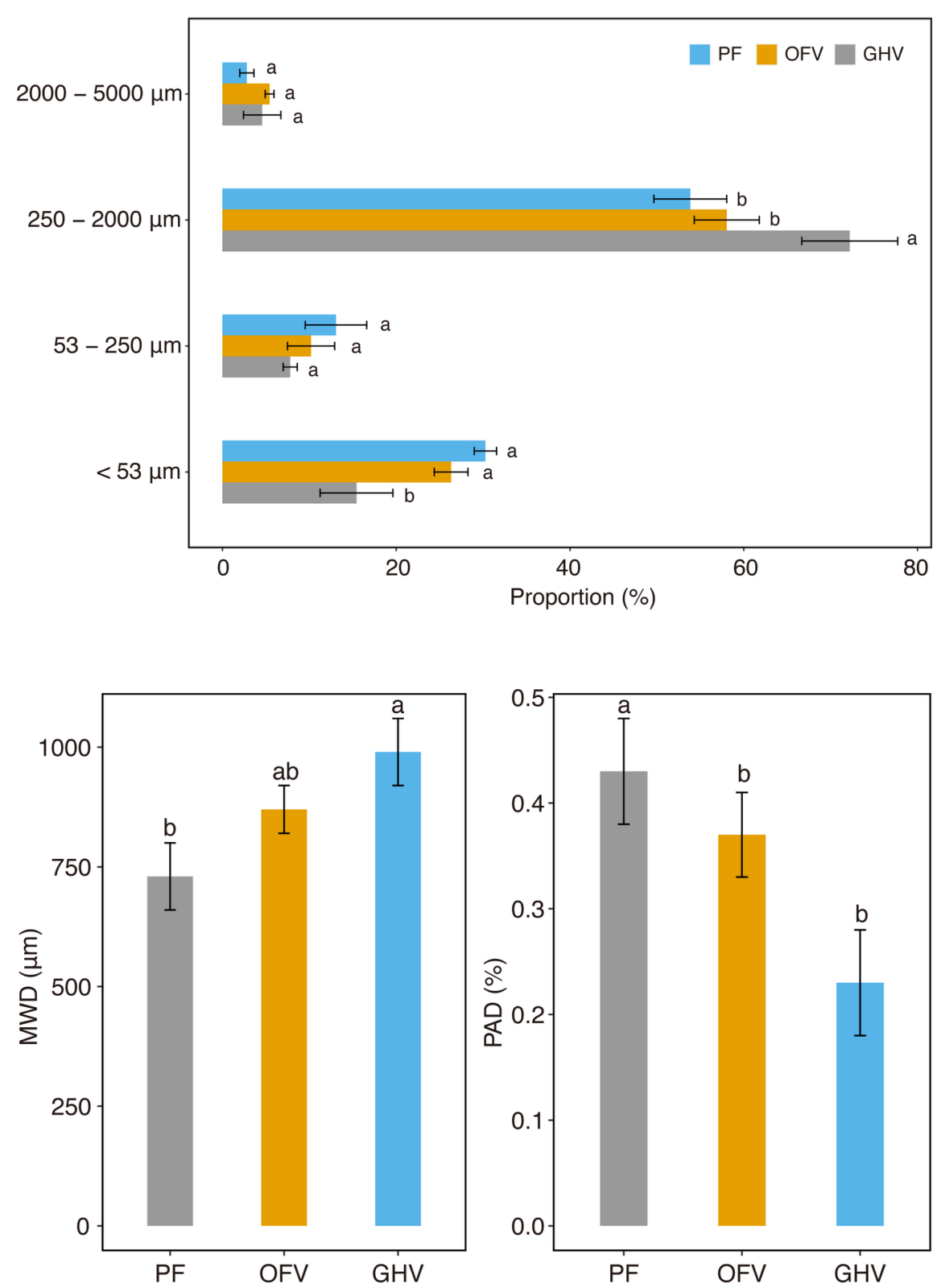


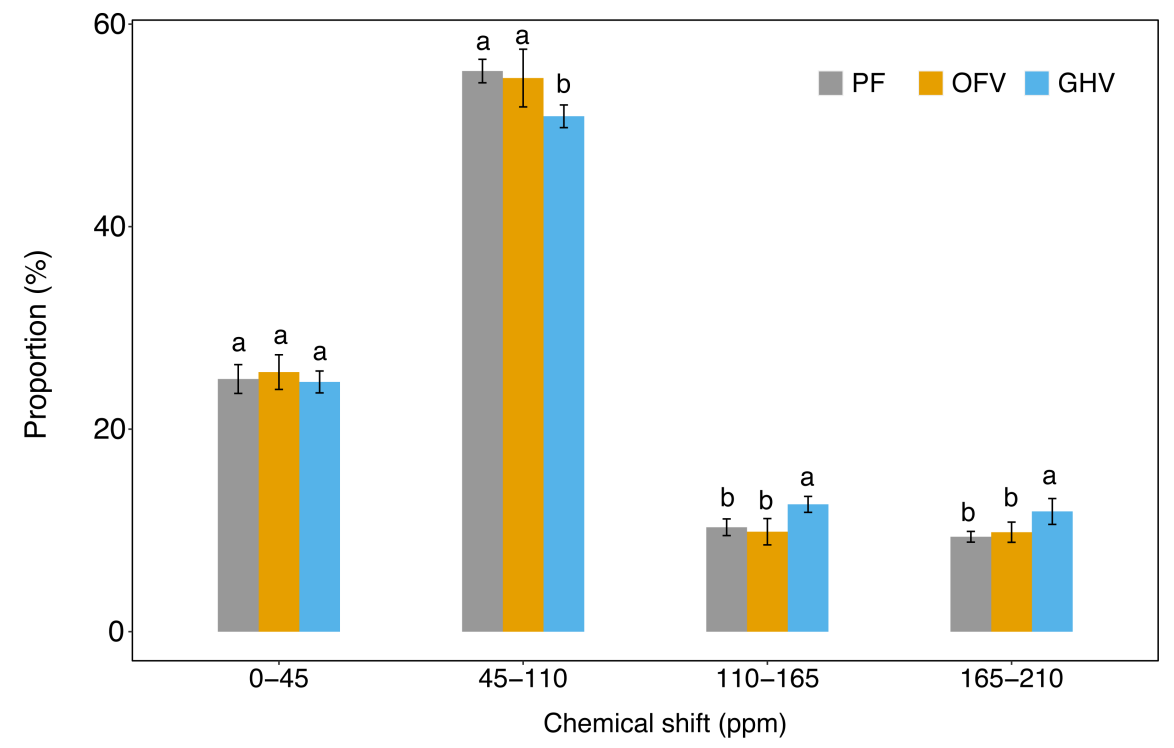

(a)

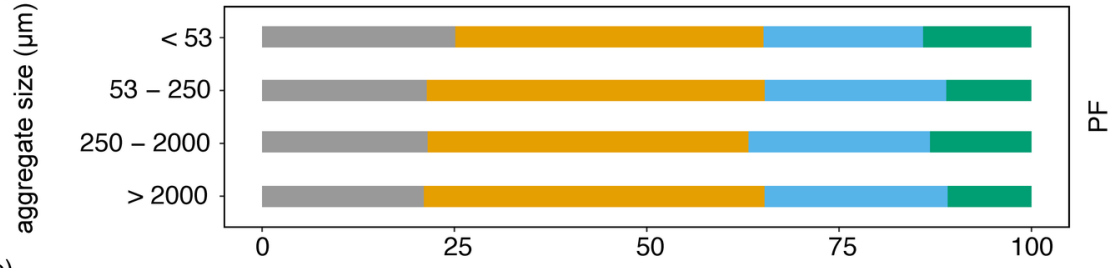

(b)

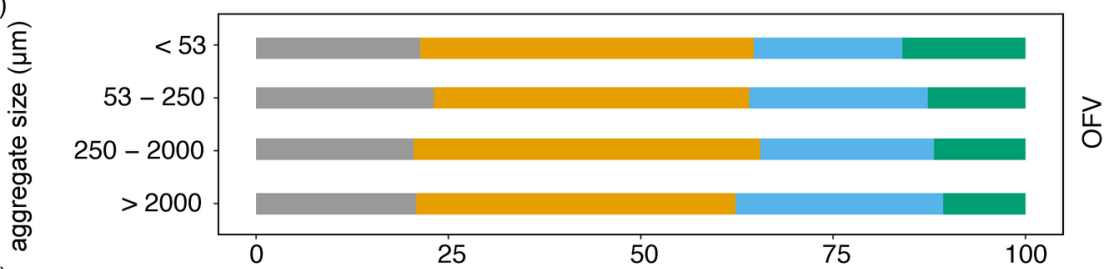

(c)

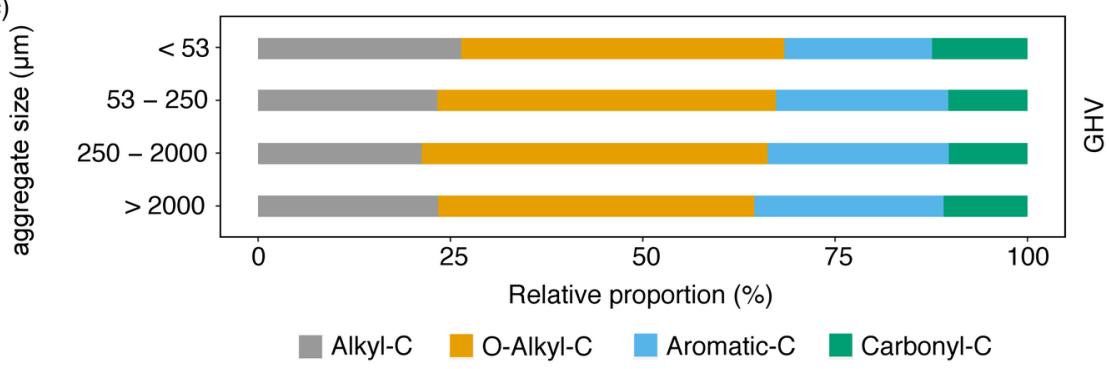




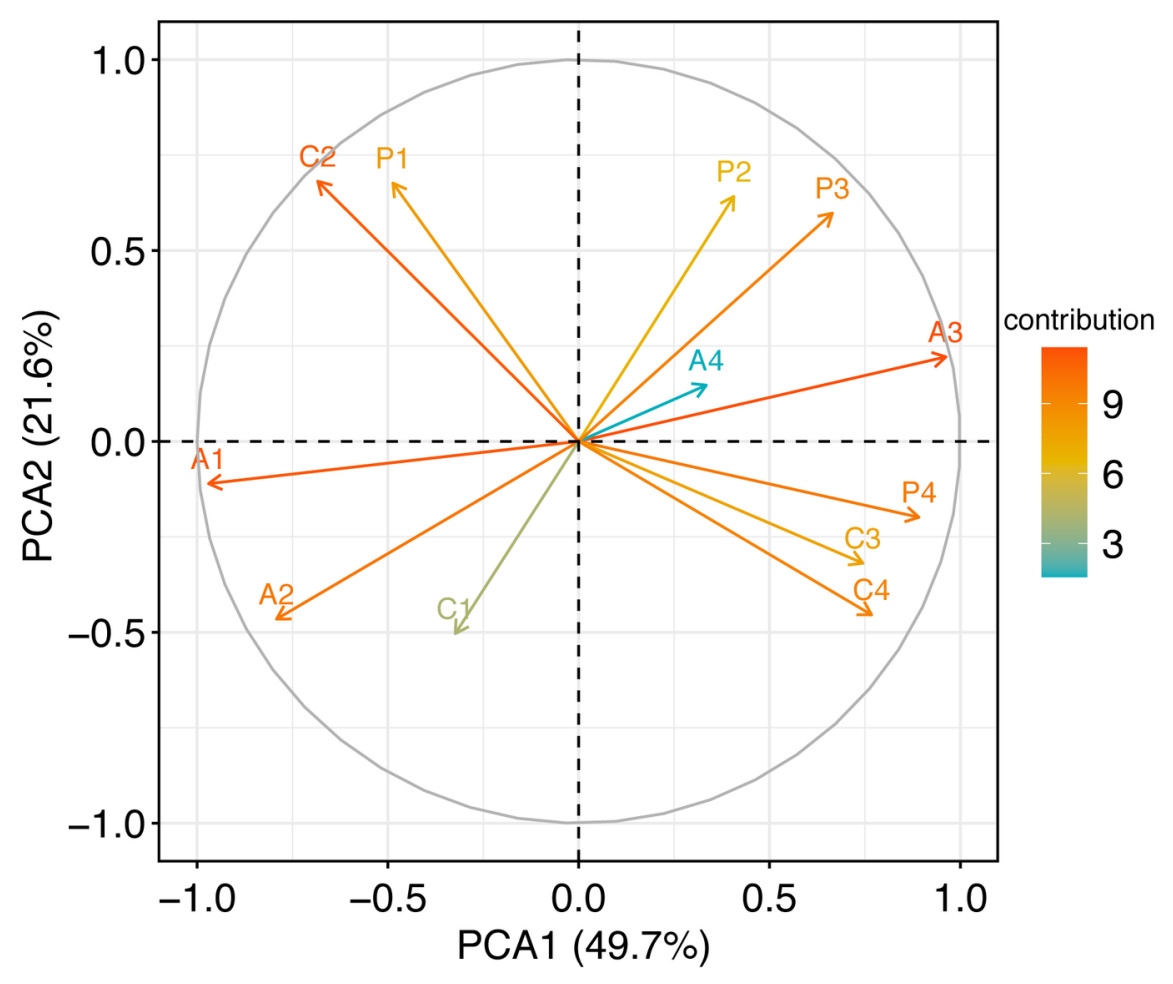

